\title{
Audit of Early and Late Maternal Deaths in Georgia: Potential for Improving Substandard Obstetric Care
}

This article was published in the following Dove Press journal: International Journal of Women's Health

\author{
Nino Berdzuli iD \\ Nino Lomia (D) \\ Anne Cathrine Staff ${ }^{1,2}$ \\ Gunta Lazdane (iD ${ }^{3}$ \\ Ekaterine Pestvenidze (ID) \\ Anne Flem Jacobsen (ID) ${ }^{1,2}$ \\ 'Institute of Clinical Medicine, Faculty of \\ Medicine, University of Oslo, Oslo, \\ Norway; ${ }^{2}$ Division of Obstetrics and \\ Gynaecology, Oslo University Hospital, \\ Oslo, Norway; ${ }^{3}$ Department of \\ Obstetrics and Gynaecology, Riga \\ Stradins University, Riga, Latvia
}

Introduction: Quality of care is an important factor in reducing preventable maternal deaths, yet it is a significant challenge in many countries. Substandard and poor quality of care is the leading factor in two-thirds of maternal deaths in European countries. Our study investigated the deaths of all women of reproductive age in 2012 in Georgia. The aim was to define the underlying causes of maternal deaths and to identify the factors in women's care which contributed to the fatal outcomes.

Methods: A national Reproductive Age Mortality Survey was conducted in Georgia in 2014-15. Data from multiple sources was triangulated to identify all deaths of women of reproductive age. This was followed by verbal autopsy diagnoses. Each case of early and late maternal death was investigated through interviews and medical record reviews at the last medical facility providing care for the deceased woman. A specialist panel reviewed and assigned underlying causes of death, assessed the management of each woman's condition, and identified elements of suboptimal care.

Results: We identified a total of 23 maternal deaths, including $15(65 \%)$ early and eight (35\%) late deaths. The maternal mortality ratio was 26.3 per 100000 live births. The four leading causes of early maternal deaths were: sepsis, hemorrhage, embolism, and pregnancyinduced hypertension. Embolism and sepsis were the direct causes of the eight late maternal deaths. Cancer, tuberculosis, and postpartum suicide constituted the indirect causes of death. Improvements in care which would have made a difference to the outcomes were identified in $87 \%$ of early maternal deaths and $67 \%$ of late maternal deaths due to direct obstetric causes.

Discussion: Delayed recognition and inappropriate management of maternal complications were common across almost all cases studied. The findings from Georgia highlight the conclusion that most maternal deaths were preventable and that improvement in obstetric care is urgently required.

Keywords: maternal mortality, late maternal death, cause of death, quality of care, maternal death preventability

\section{Introduction}

Although maternal mortality has declined globally by $38 \%$ over the past two decades, ${ }^{1}$ the dominant and most common direct causes of maternal death remain postpartum hemorrhage, hypertensive disorders and maternal sepsis. ${ }^{2}$ Still, indirect causes have been playing an increasing role in maternal mortality, globally. ${ }^{3,4}$ These causes include cardiovascular disease, cancer, mental health disorders, infectious diseases and nongenital sepsis. ${ }^{3,4}$
Correspondence: Nino Berdzuli Institute of Clinical Medicine, Faculty of Medicine, University of Oslo, Oslo, Norway

Tel +4530354465

Email nbniaber@gmail.com
International Journal of Women's Health 202I:I3 205-219 
While the maternal mortality ratio in Europe is relatively low in comparison with other regions of the world, there is a wide variation in the European Region ${ }^{1}\left({ }^{1} \mathrm{As}\right.$ defined by the World Health Organization (WHO), the European Region comprises 53 countries, covering a vast geographical region from the Atlantic to the Pacific oceans.) across countries both in terms of mortality rates and causes of maternal deaths. ${ }^{1}$ Importantly, low-income countries have higher levels of maternal deaths from direct obstetric causes in contrast to high-income countries, which are experiencing increasing levels of maternal mortality from indirect causes. This is likely due to the rise in non-communicable diseases (NCDs).

The "three delays" model of maternal care identifies three time points when appropriate interventions can prevent an emergency condition from progressing toward a maternal death. These delays are: (1) in seeking care; (2) in reaching a care facility; and (3) in receiving appropriate care. ${ }^{5}$ This model is commonly applied to evaluate factors that may impede women from receiving appropriate medical care. It is estimated that $50-70 \%$ of maternal deaths can be prevented simply by assuring that women have access to appropriate and good quality of care. ${ }^{6,7}$ Thus, quality of care is an important factor in reducing preventable maternal deaths and a significant challenge in many countries. As shown by confidential enquiries, substandard and poor quality of care is the leading factor in two thirds of maternal deaths in European countries. ${ }^{8}$

The factors influencing quality are complex and interconnected. They include: the availability of infrastructure and supplies; level of training of health care personnel; preparedness of facilities to provide required levels of specialized care when complications arise; adequate and rapid referral systems; and provider-patient relationships. ${ }^{9,10}$ Other factors include leadership, governance and accountability for quality. In low- and middleincome countries, maternal mortality reduction is slow due to the limited quality of services provided, combined with poor health system capacity to timely identify and adequately manage pregnancy complications. ${ }^{11}$

Monitoring and clinical auditing of individual maternal deaths, both early and late, can provide insights into different aspects of the quality of services provided and then help define the elements of delay and substandard care which need to be addressed. This process is central for detecting gaps in the health system and recommending policies and improvements to health care decision makers. ${ }^{12}$ In addition, many countries focus efforts solely on prevention of early maternal death and too often fail to link late maternal death with missed opportunities in care during pregnancy or after delivery. ${ }^{13}$ A late maternal death is defined as death of a woman from direct or indirect causes more than 42 days but less than one year after the end of pregnancy. It has been introduced in the International Classification of Diseases (ICD) $10^{\text {th }}$ Revision because of the current advancements in medical care potentially delaying death after lifethreatening complications of pregnancy. ${ }^{14}$ Despite its importance, reporting and examining of late maternal deaths has to date been insufficient.

A Reproductive Age Mortality Survey (RAMOS) was conducted in Georgia in 2014 (RAMOS14) in order to ascertain the accuracy of routine statistics and to understand the epidemiology of maternal mortality and its determinants. RAMOS used retrospective data from $2012^{15}$ and assessed the magnitude of maternal mortality and its causes, enabling a comparison to a similar survey conducted in 2008, based on 2006 data. In this study, we assessed each maternal death and identified the main causes of death as well as contributing factors. We also assessed the elements of substandard medical care, including timely identification of risks or complications, adequate and timely referral to the appropriate level obstetric facility, evidence-based management of severe maternal conditions, and timely interventions. Importantly, the study also addresses late maternal deaths, contributing to the knowledge base around these deaths.

\section{Materials and Methods Study Population}

The national RAMOS was conducted between March 2014 and January 2015. The study's target population included all women aged 15 to 49 who were permanent residents in Georgia, and who died in 2012. The year 2012 was selected as the most recent year for which full and error-checked databases were available at the time the study began.

\section{Standard Definitions}

In this study we used the World Health Organization (WHO) ICD-Maternal Mortality (ICD-MM) definition of maternal death and underlying causes of death classification and applied these definitions to all reviewed maternal deaths:

A maternal death is the death of a woman while pregnant or within 42 days of termination of pregnancy, irrespective of the duration and the site of the pregnancy, from any 
cause related to or aggravated by the pregnancy or its management, but not from accidental or incidental causes.

We also applied the definition of late maternal deaths as "delayed deaths occurring between full six weeks (more than 42 days) and one year postpartum". ${ }^{16}$ All maternal deaths were included and classified based on their causes as either direct or indirect. Direct obstetric deaths were standardly defined as

those resulting from obstetric complications of the pregnancy state (pregnancy, labor and the puerperium), from interventions, omissions, incorrect treatment, or from a chain of events resulting from any of the above.

Indirect obstetric deaths were those resulting from previous existing disease or disease which developed during pregnancy and which was not due to direct obstetric causes, but which was aggravated by physiologic effects of pregnancy. ${ }^{16}$

\section{Data Collection}

The triangulation of data from multiple sources was applied to identify potentially eligible women of reproductive age (WRA). Data sources included: 1) the civil registration and vital statistics (CRVS) mortality electronic dataset; 2) routine health statistics and surveillance data from the National Center for Disease Control and Public Health (NCDC\&PH) of Georgia; 3) hospital and ambulance service registers and electronic datasets; 4) regional death registers; and 5) community informants contacted during the field investigations. The 2012 number of live births $(57,002)$ reported in the official statistics, CRVS and NCDC \&PH data sources, was used to yield maternal deaths per 100,000 live births.

Of the 913 eligible deaths of WRA in 2012 in Georgia, 36 were identified as pregnancy- related deaths (Figure 1). A multidisciplinary panel of medical experts reviewed the medical records of all 36 women who died during pregnancy or within 1 year of termination of their pregnancy, categorized the pregnancy-related deaths as maternal deaths ("direct" or "indirect") or as "co-incidental". The review identified 13 deaths as co-incidental. For the 23 deaths categorized as maternal, a panel of experts conducted additional in-depth reviews of the treatment and care provided to the women and commented on the quality of care and preventability of the death.

The review team considered the existing Georgian national guidelines and clinical care protocols as the reference standard of care for evaluating timely recognition and treatment, appropriate management and referral. Where local guidelines were lacking, we applied guidelines from the Royal College of Obstetricians and Gynecologists (RCOG), ${ }^{17,18}$ American College of Obstetricians and Gynecologists (ACOG), ${ }^{19}$ and WHO. $^{20-22}$ Categorization of the quality of care was made based on the United Kingdom's (UK) scoring system ${ }^{3}$ as follows: 1 - good care, 2 - improvements to care which would have made no difference to the outcome, and 3 - improvements to care which would have made a difference to the outcome.

\section{Statistical Analyses}

The SPSS version 21.0 (IBM, Armonk, NY, USA) was used to analyze mortality data. We applied univariate, stratified analyses, constructed frequency tables and performed cross tabulation to investigate patterns of maternal mortality in Georgia. The overall MMR was calculated as number of all maternal deaths per 100000 live births.

\section{Ethical Approval}

The study protocol was approved by the Georgian Institutional Review Boards of NCDC \& PH (IRB 2017-035 and 2019-013) and the Regional Committees for Medical and Health Research Ethics South East Norway (2015/1352). Written informed consent was obtained from all respondents (family members or caretakers of the deceased women) prior to the interviews.

\section{Results}

The study identified a total of 23 maternal deaths during 2012, including 15 (65\%) early and eight (35\%) late maternal deaths. The overall MMR was 40.3 per 100000 live births, early MMR was 26.3 per 100000 live birth. Of the fifteen early maternal deaths, 14 (93\%) were direct and one $(7 \%)$ indirect.

\section{Causes of Maternal Death}

The leading causes of maternal deaths were sepsis $(n=5)$, hemorrhage $(n=3)$, pregnancy-induced hypertension $(\mathrm{PIH})$ $(n=2)$ and embolism $(n=1)$ In other direct causes category, sudden death, unanticipated complication of anesthesia during delivery and complication following intrauterine fetal death, were one death in each (Figure 2). Direct causes of the late maternal deaths were: embolism $(n=2)$ and sepsis $(n=1)$. Indirect causes were cancer $(n=3)$, tuberculosis $(n=1)$, and postpartum suicide $(n=1)$. Coincidental 


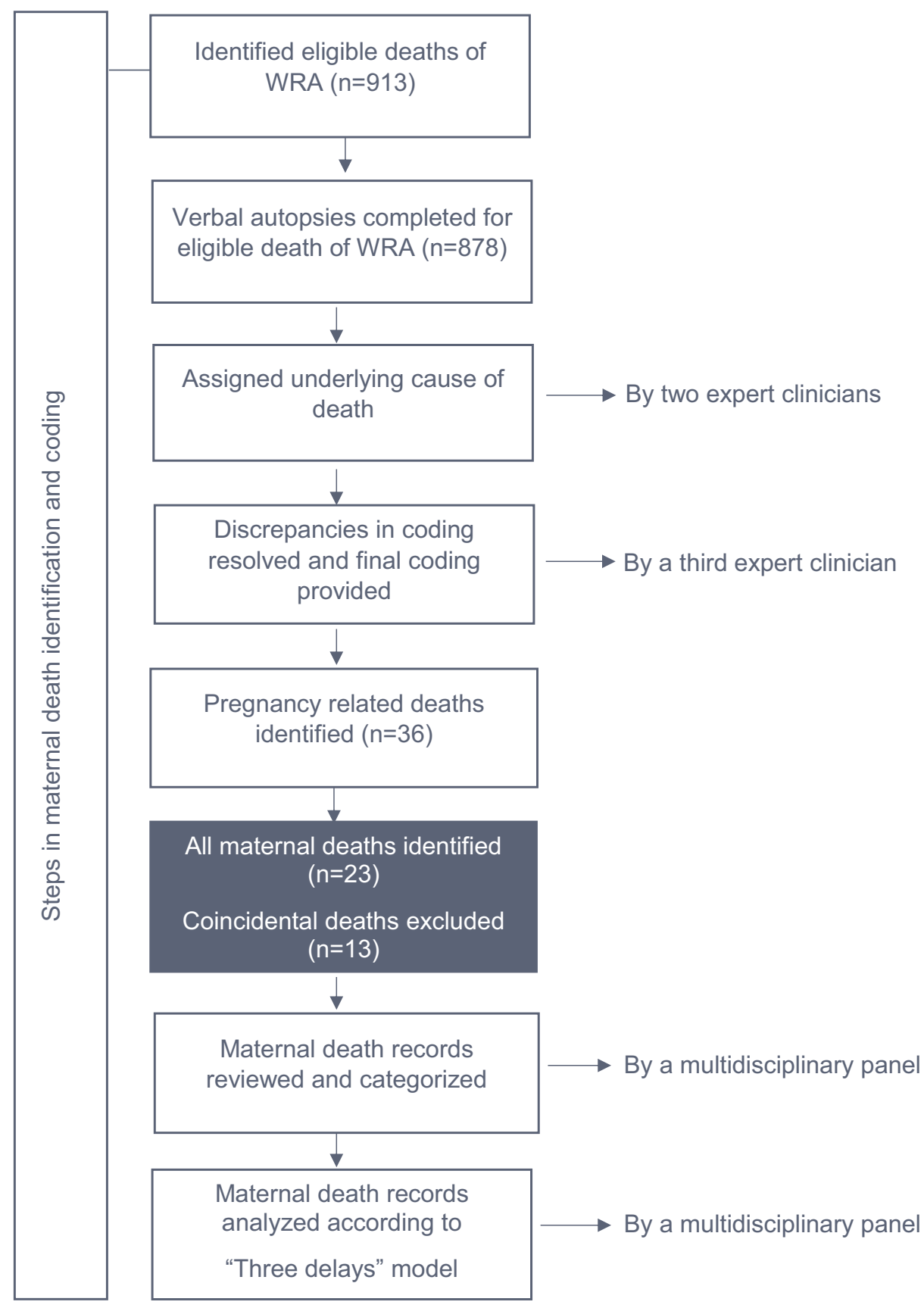

Figure I Maternal death identification and coding, Georgia, 2012.

causes (13), unrelated to pregnancy, were due to transport and other accidents $(\mathrm{n}=6)$, cancer $(\mathrm{n}=6)$ and liver cirrhosis.

\section{Selected Characteristics of Women in Relation Causes of Mortality}

The study showed that the majority (over 50\%) of maternal deaths were among women aged $21-30$ years. Importantly, the number of deceased women delivered by cesarean section was twice as high compared to vaginal deliveries (eight and four, respectively). As many as $26 \%(\mathrm{n}=6)$ of deaths occurred post-abortion or from ectopic pregnancy. These included early fetal loss (three miscarriages) and two induced abortions, one from a self-attempted termination. Finally, $13 \%(n=5)$ of women were still pregnant at the time of death. Women who died from sepsis and embolism tended to deliver by cesarean section and were younger (range 21-30) as compared to the older age groups (Table 1). 


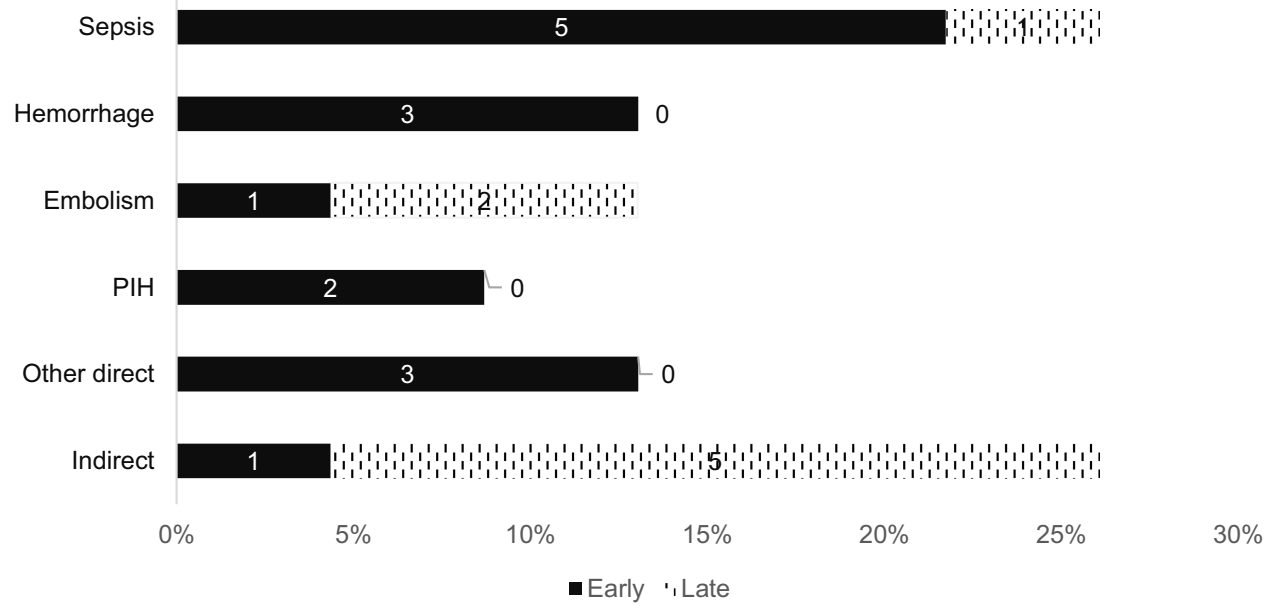

Figure 2 Causes of maternal deaths by time of death, Georgia, 2012.

\section{Overview of Care}

Overall, we found that suboptimal care was provided in 13 (87\%) out of 15 early maternal deaths. Similarly, improvements in care which would have made a difference to the outcome in two $(67 \%)$ of the three late maternal deaths due to direct obstetric causes.

\section{Early Recognition and Appropriate Management}

Our study found that delayed recognition of a severe or lifethreatening condition was a significant problem. Out of the 23 cases of maternal death, only one (4\%) was identified in a timely way. The other $16(70 \%)$ were detected with delays and for six (26\%) indirect deaths, timely identification of the problem was not a relevant factor. Along with delayed recognition, deficiencies were evident in the management of complications in many death cases (65\%) (Figure 3).

There were delays in recognizing all sepsis cases (five were early and one was a late death). A significant problem identified was timely recognition of the clinical signs suggestive of infection (Table 2: case 4, case 9 and case 16). Some of the cases (eg case 16, Table 2) evidenced a delay in both timely recognition and treatment of sepsis. Medical records were deficient in half of the sepsis cases, which were missing a full set of vital parameters on day

Table I Selected Characteristics of 23 Maternal Deaths by Main Cause of Death (in Columns), Georgia, 2012

\begin{tabular}{|c|c|c|c|c|c|c|c|}
\hline Characteristics & $\begin{array}{l}\text { Sepsis/Septic } \\
\text { Shock } \\
(n=6)\end{array}$ & $\begin{array}{l}\text { Obstetric } \\
\text { Hemorrhage }(n=3)\end{array}$ & $\begin{array}{l}\text { Embolism } \\
(n=3)\end{array}$ & $\begin{array}{l}\text { Preeclampsia/ } \\
\text { Eclampsia } \\
(n=2)\end{array}$ & $\begin{array}{l}\text { Other } \\
\text { Direct } \\
(n=3)\end{array}$ & $\begin{array}{l}\text { Indirect } \\
(n=6)\end{array}$ & $\begin{array}{l}\text { All } \\
(n=23)\end{array}$ \\
\hline $\begin{array}{l}\text { Age, years } \\
21-30 \\
31-40 \\
\geqq 40\end{array}$ & $\begin{array}{l}4 \\
2\end{array}$ & $\begin{array}{l}1 \\
1 \\
1\end{array}$ & $\begin{array}{l}2 \\
1\end{array}$ & $\begin{array}{l}1 \\
1\end{array}$ & $\begin{array}{l}2 \\
1\end{array}$ & $\begin{array}{l}3 \\
2 \\
1\end{array}$ & $\begin{array}{l}12 \\
7 \\
4\end{array}$ \\
\hline $\begin{array}{l}\text { Delivery mode } \\
\text { Miscarriage/ectopic } \\
\text { pregnancy } \\
\text { Induced abortion } \\
\text { Vaginal delivery } \\
\text { Caesarean delivery } \\
\text { Undelivered/pregnant }\end{array}$ & $\begin{array}{l}1 \\
1 \\
1 \\
3\end{array}$ & 2 & $\begin{array}{l}1 \\
2\end{array}$ & 2 & $\begin{array}{l}1 \\
2\end{array}$ & $\begin{array}{l}1 \\
1 \\
1 \\
2 \\
1\end{array}$ & $\begin{array}{l}4 \\
2 \\
4 \\
8 \\
5\end{array}$ \\
\hline $\begin{array}{l}\text { Time of death } \\
\text { Antepartum } \\
\text { Post-abortion } \\
\text { Postpartum }\end{array}$ & $\begin{array}{l}2 \\
4\end{array}$ & $\begin{array}{l}2 \\
1\end{array}$ & 3 & 2 & 2 & $\begin{array}{l}1 \\
2 \\
3\end{array}$ & $\begin{array}{l}5 \\
6 \\
12\end{array}$ \\
\hline
\end{tabular}




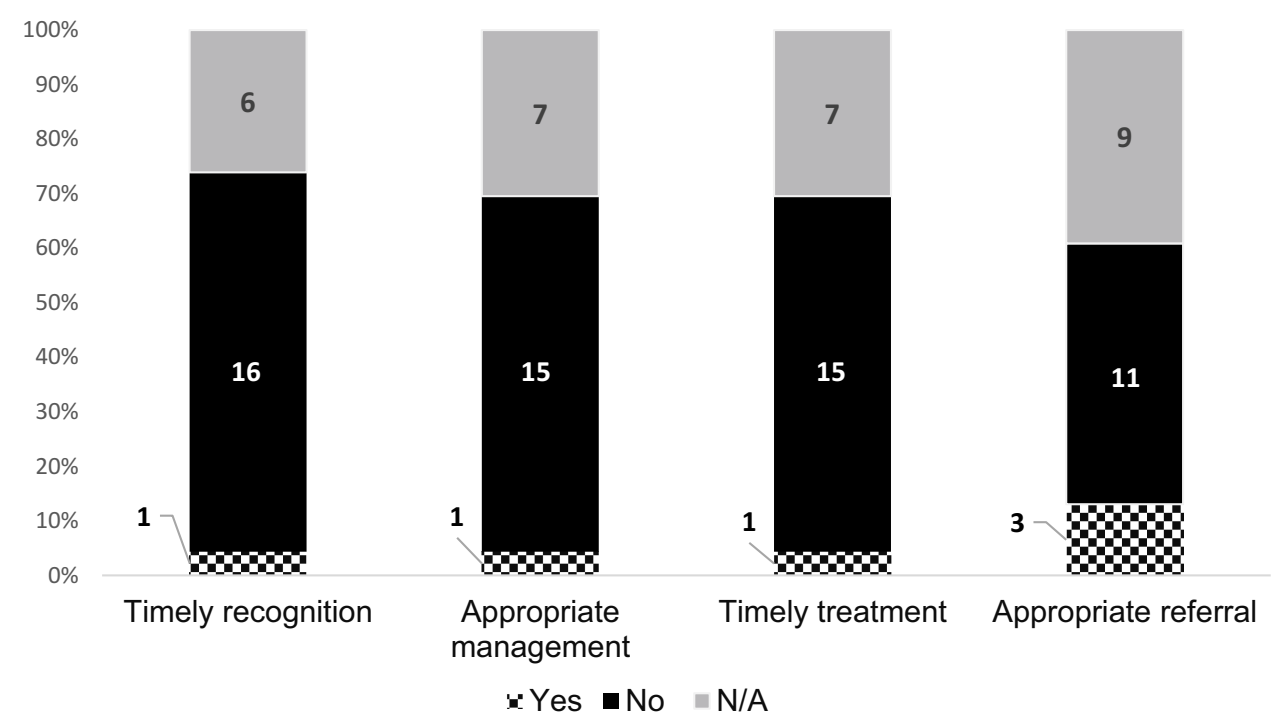

Figure 3 Evaluation of care provided to 23 deceased women by key characteristics, Georgia, 2012.

preceding to or at a time when the diagnoses of infection was made. Additionally, gaps were documented in timing and spectrum of laboratory testing. No blood or other samples were drawn for bacterial culture for presumed infection in five out of six sepsis cases. Although antibiotic therapy was initiated in most cases on the same day as infection was suspected, the delays and use of a proper antibiotic regimen was a significant problem.

Poor management was identified in all three fatal cases of obstetric hemorrhage. The management did not follow any of three basic principles of patient safety: the right patient, the right place, and the right procedure (case 3, Table 2). Although the uterine perforation was detected on time, the curettage was initially performed in a facility where complications could not be properly managed. The woman was transported to another specialized facility without prior stabilization. Her condition deteriorated during transportation. Stabilization measures also were inadequate in the referral hospital. A total hysterectomy was then performed instead of repairing the hole in the posterior wall of the uterus.

In one case of hemorrhage after a spontaneous abortion at mid-pregnancy (case 5, Table 2), the team misinterpreted the clinical signs as bleeding from a cervical laceration. A hysterectomy was conducted too late and failed to save the woman's life.

Similarly, we identified inadequate management of postpartum uterine atony (case 11, Table 2). Initial blood loss was underestimated. Surgical management and hysterectomy were delayed, and insufficient blood transfusion was applied, despite hemodynamic instability (with a hemoglobin of $50 \mathrm{~g} / \mathrm{L}$, and hematocrit of $6.8 \%$ ).

Poor prophylaxis and management were evident in two of three cases of thromboembolic maternal deaths but had probably no association with the last case due to the time lag of 133 days (case 2 and case 17, Table 2).

Finally, in-depth clinical audit disclosed substantial deficiencies in preeclampsia management. Two women who died from severe preeclampsia had inadequate monitoring of blood pressure and lack effective antihypertensive treatment. Conversely, another woman (case 6, Table 2) received a loading intravenous overdose of magnesium sulfate ( $10 \mathrm{~g}$ instead of the recommended $4 \mathrm{~g})$. This woman's condition deteriorated within one hour after the toxic dose suggestive of hypermagnesemia.

\section{Maternal Referral}

Along with deficiencies in early recognition and management of maternal complications, the study documented inappropriate and/or delayed referral in 11 (79\%) out of 14 cases requiring referral (Figure 2). In six cases of early maternal deaths, the women were not referred in a timely manner or were referred to inappropriate level facilities.

\section{Discussion}

Our study is among the first analyzing the magnitude and pattern of both early and late maternal deaths in Georgia during 2012. Of the eight late maternal deaths identified in the present study, most (7/8: 88\%) were unrecognized by the official statistics as maternal deaths. Direct cause of 


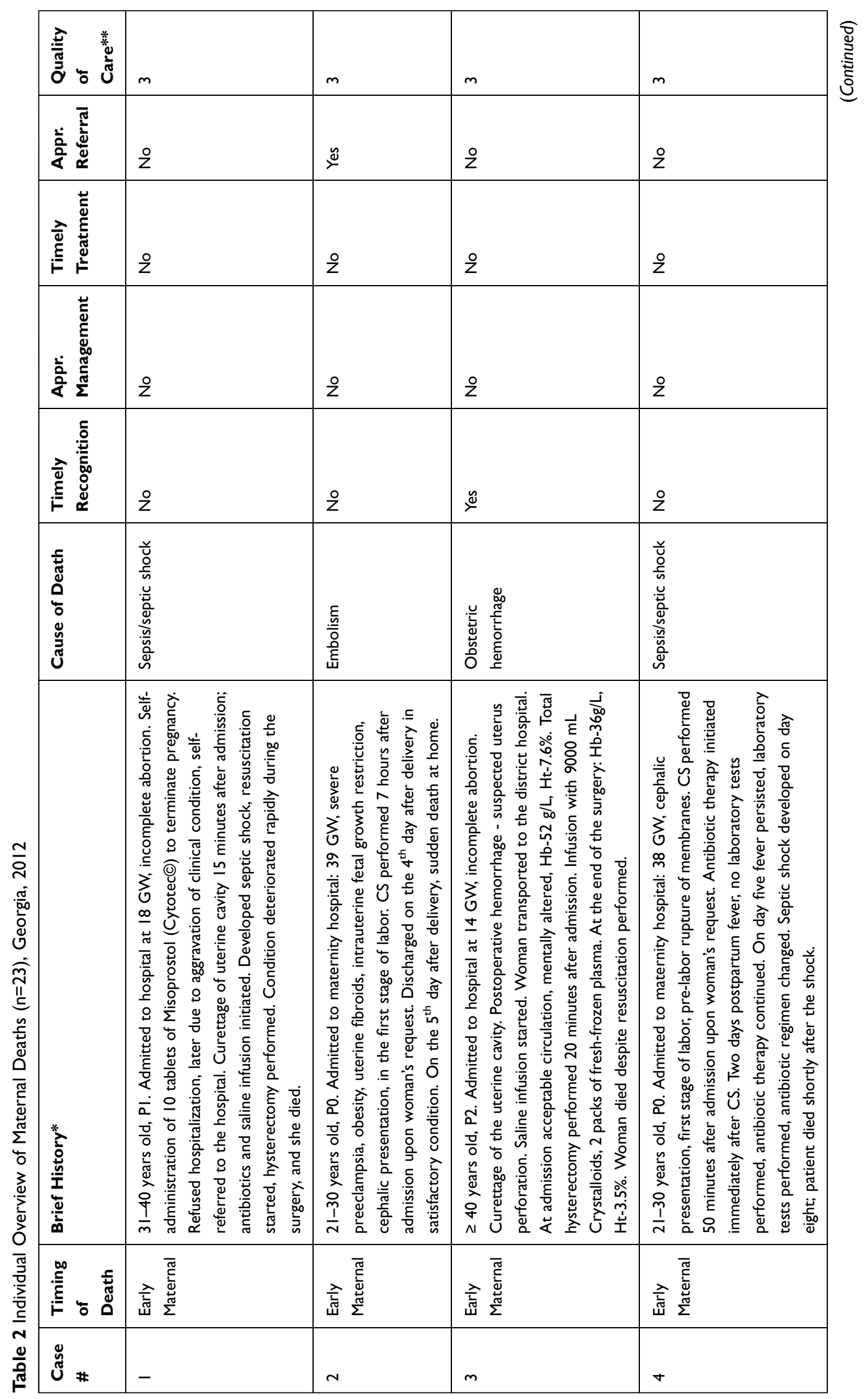




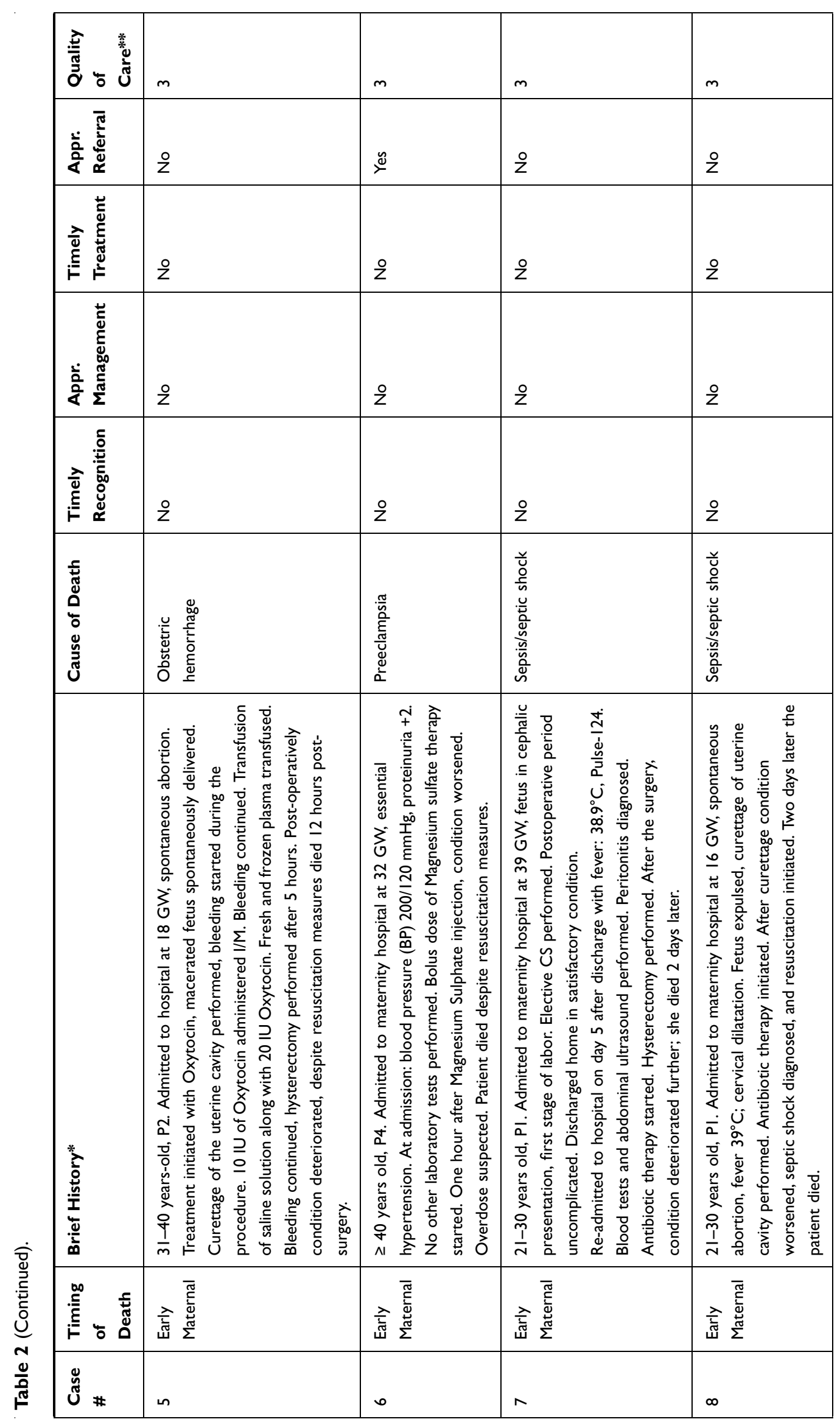




\begin{tabular}{|c|c|c|c|c|c|c|}
\hline$m$ & $m$ & $m$ & $\sim$ & $m$ & $\widehat{\Sigma}$ & $m$ \\
\hline$\stackrel{\circ}{z}$ & $\stackrel{\circ}{z}$ & $\frac{\bar{z}}{z}$ & $\stackrel{\circ}{z}$ & 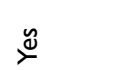 & $\frac{\bar{z}}{z}$ & $\stackrel{\mathscr{ٌ}}{0}$ \\
\hline$\stackrel{0}{z}$ & 울 & zo & $\mathscr{\mathscr { g }}$ & $\stackrel{\circ}{z}$ & $\widehat{\bar{z}}$ & $\stackrel{\circ}{z}$ \\
\hline$\stackrel{0}{z}$ & 울 & zo & $\stackrel{\mathscr{g}}{0}$ & $\stackrel{\circ}{z}$ & $\frac{\$}{z}$ & $\stackrel{\circ}{z}$ \\
\hline$\stackrel{\circ}{z}$ & $\stackrel{\circ}{z}$ & 운 & $\stackrel{\circ}{z}$ & 울 & $\widehat{s}$ & $\stackrel{\circ}{z}$ \\
\hline 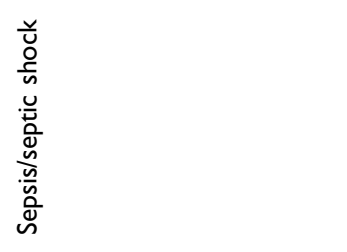 & 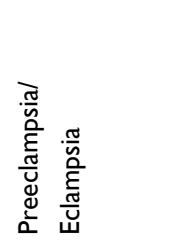 & 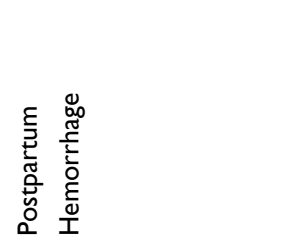 & 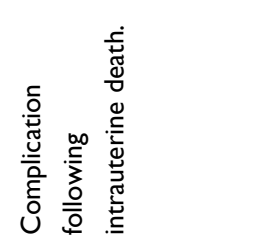 & 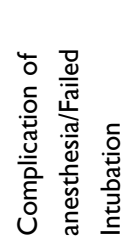 & 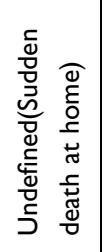 & 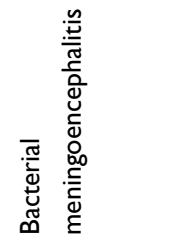 \\
\hline 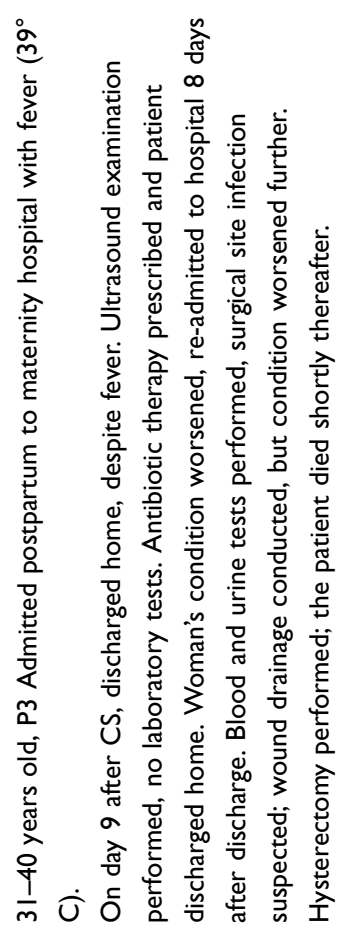 & 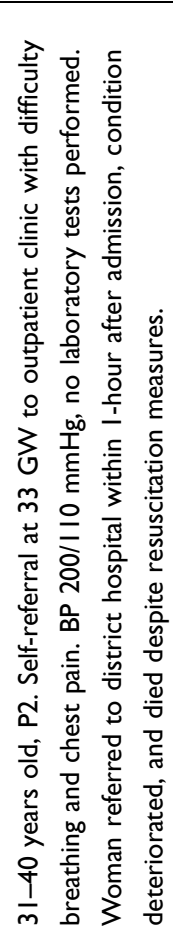 & 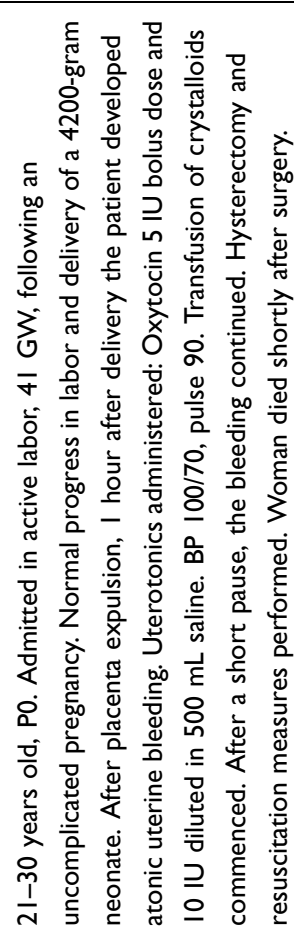 & 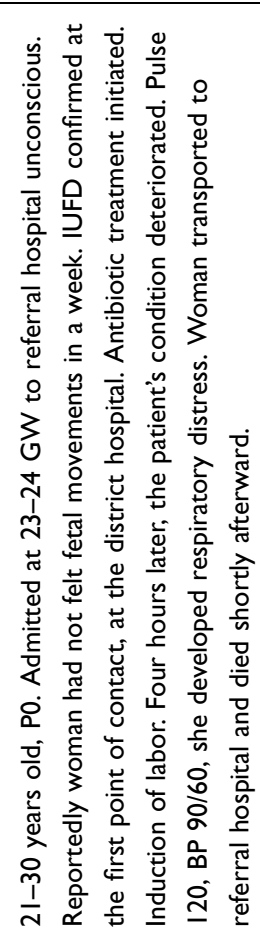 & 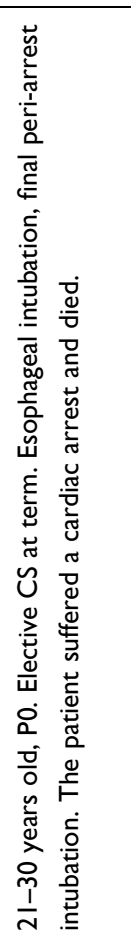 & 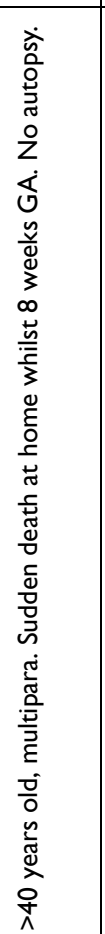 & 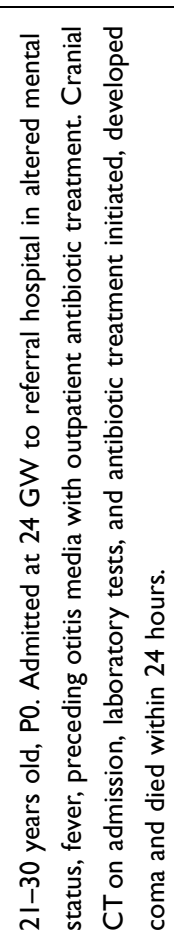 \\
\hline 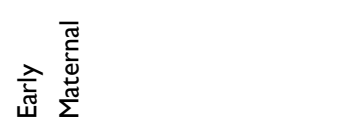 & 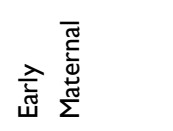 & 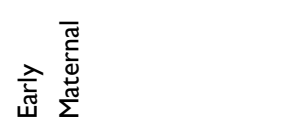 & 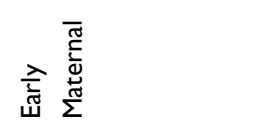 & 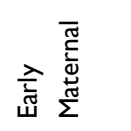 & 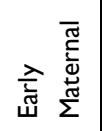 & 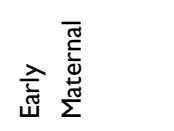 \\
\hline$\sigma$ & 으 & $=$ & $\simeq$ & $\underline{m}$ & \pm & $\underline{\underline{n}}$ \\
\hline
\end{tabular}




\begin{tabular}{|c|c|c|c|c|c|c|c|c|c|}
\hline 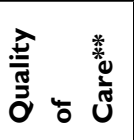 & $m$ & $m$ & 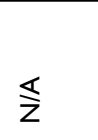 & 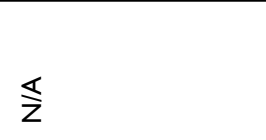 & $m$ & 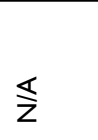 & $\ll$ & 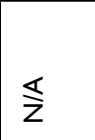 & 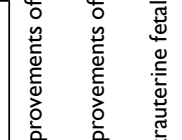 \\
\hline 畜 & $\stackrel{\varpi}{\check{N}}$ & 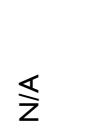 & 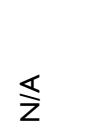 & 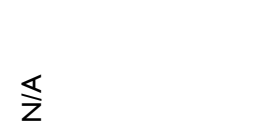 & 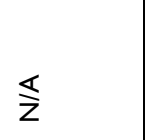 & $\stackrel{\nwarrow}{\mathbf{z}}$ & 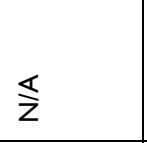 & 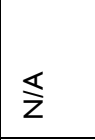 & 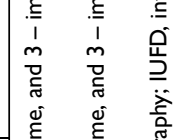 \\
\hline 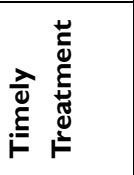 & 을 & 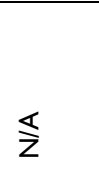 & 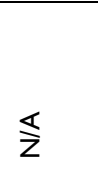 & 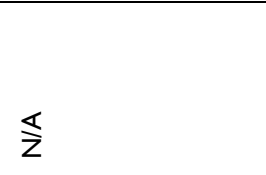 & 우 & $\stackrel{\varangle}{z}$ & $\stackrel{\varangle}{z}$ & 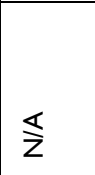 & 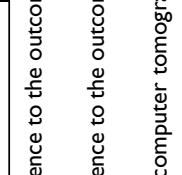 \\
\hline 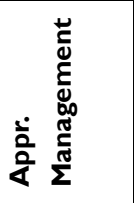 & ㅇ & 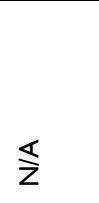 & 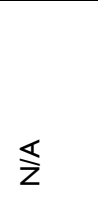 & $\$$ & $\stackrel{\circ}{z}$ & $\stackrel{\varangle}{z}$ & 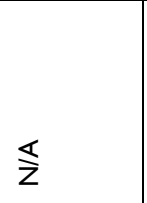 & 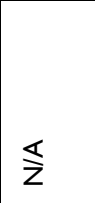 & 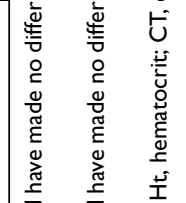 \\
\hline 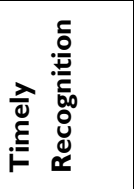 & 으 & 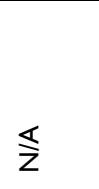 & 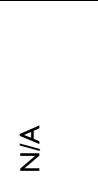 & 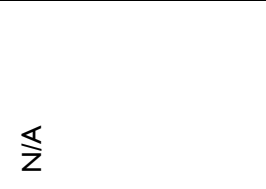 & $\stackrel{0}{z}$ & 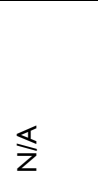 & $\mathbb{z}$ & z & 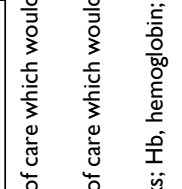 \\
\hline 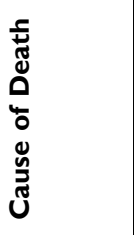 & 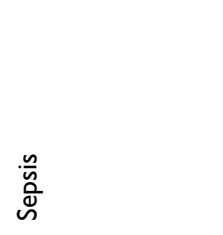 & 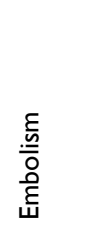 & 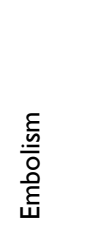 & 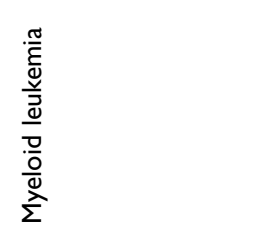 & $\begin{array}{l}\frac{n}{0} \\
\frac{0}{\bar{J}} \\
\bar{\nu} \\
\stackrel{0}{F}\end{array}$ & 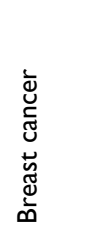 & 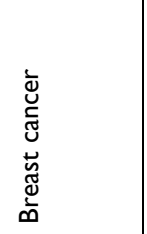 & $\begin{array}{l}\frac{0}{0} \\
: \frac{\overline{0}}{5} \\
\overline{5}\end{array}$ & 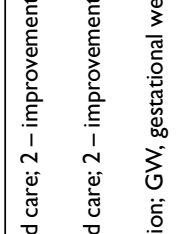 \\
\hline 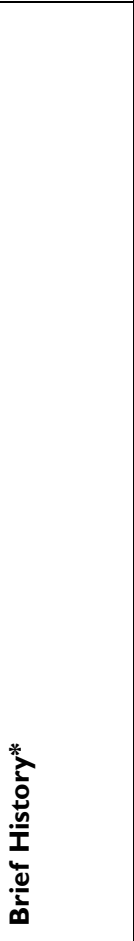 & 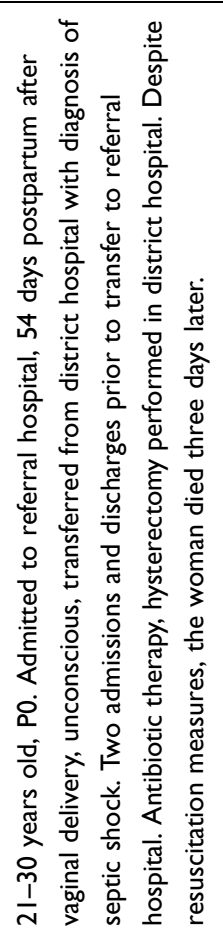 & 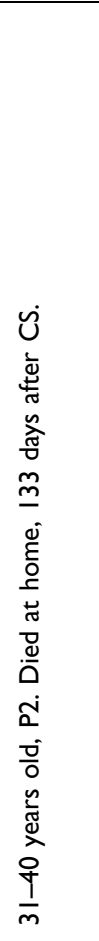 & 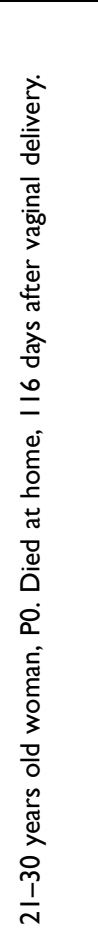 & 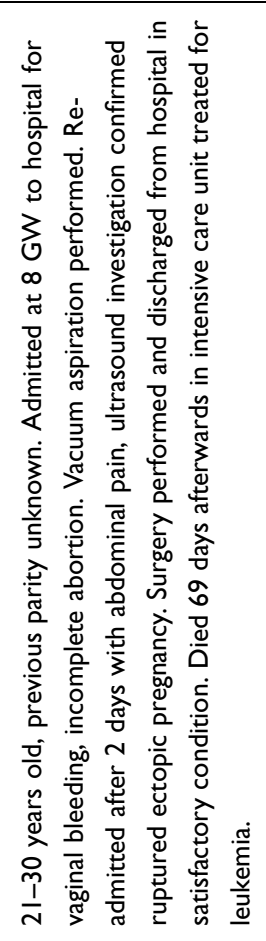 & 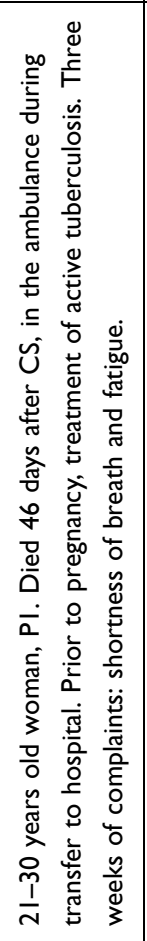 & 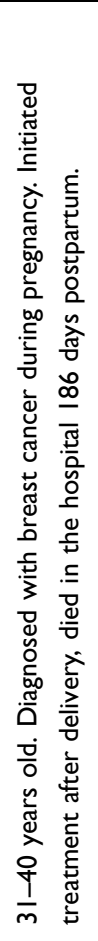 & 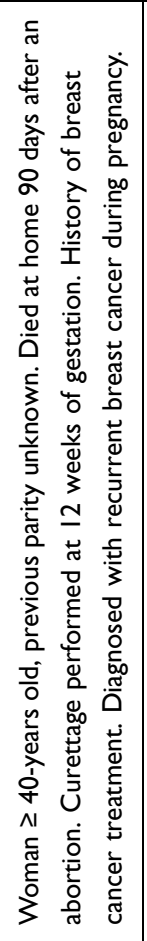 & 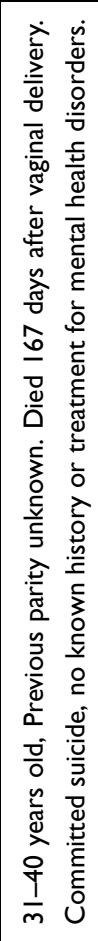 & 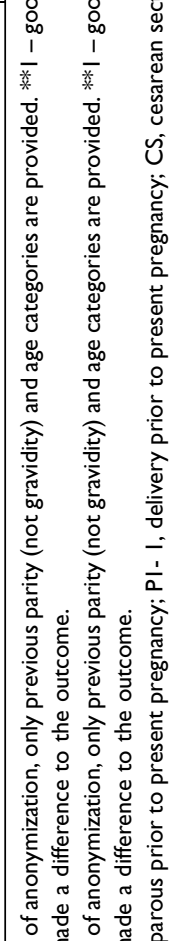 \\
\hline 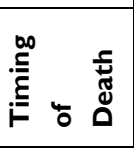 & 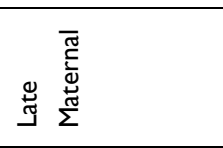 & 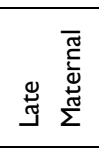 & 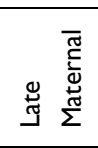 & 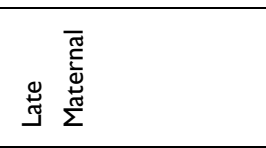 & 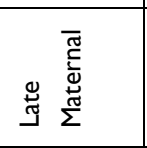 & 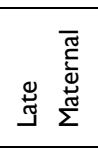 & 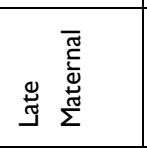 & 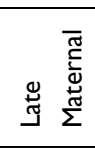 & $\frac{D}{3}$ \\
\hline 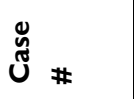 & $\underline{\bullet}$ & $\simeq$ & $\underline{\infty}$ & $\underline{a}$ & i & $\bar{N}$ & ส & $\stackrel{\sim}{\sim}$ & \\
\hline
\end{tabular}


one officially reported late maternal death following ectopic pregnancy was reclassified as indirect only after the comprehensive case review, while other late maternal deaths were misclassified in other ICD-10 chapters.

With the introduction of an electronic notification system, it is noteworthy that the remarkable progress has been achieved in Georgia in death registration coverage, and the death certification process has improved. However, despite well documented improvements, the quality of cause-ofdeath certification and coding has still been overlooked by Georgia's vital registration system. Most pregnancy checkboxes remain empty within one year postpartum following a maternal death. This study's association between death and pregnancy was made possible only through data matching or birth records linkage. The coupling of pregnancy and female deaths is particularly challenging with deaths occurring during pregnancy, after abortion, or any deaths due to indirect obstetric causes. Official statistics systems have not captured late maternal death in many countries who have conducted confidential enquiries, including Denmark, Ireland, Finland, and the UK. ${ }^{23}$ Our study confirms that the complications of pregnancy and birth may surpass 42 days postpartum. It underscores the importance of monitoring, proper classification and the integration of late maternal death into official statistics.

Most of the late maternal deaths documented in our study were indirect, with the leading cause being malignant neoplasms. This finding is in line with a prior study from Italy, where cancer was a leading cause of late maternal deaths, occurring in $38.8 \%{ }^{13}$ Another indirect cause of late maternal death was tuberculosis. The outcome for pregnant women with tuberculosis is poorer, with a six-fold increase in the risk of maternal mortality. ${ }^{24}$ Treatment adherence in previous treatment episodes was the cause of an ensuing maternal death from tuberculosis in our study. While the proportion of successfully treated patients with tuberculosis has improved markedly among new cases, Georgia still has a high percentage $(27 \%)$ of clinical failure or poor treatment adherence in previous tuberculosis treatment episodes. ${ }^{25}$ Overall, critical aspects of care among the late maternal deaths were indicative of deficiencies in preconception care in Georgia, where an improvement might have prevented or limited some maternal deaths. Preconception care provides critical opportunities to detect and manage chronic diseases and other health risks, and better protect the health of women with non-communicable as well as communicable diseases and their offspring.
In addition to identifying the causes of maternal death, the individual death audits provide important insights into the organization and delivery of maternal health services in Georgia. Overall, the study showed deficiencies and delays at all stages of provision of care. While analyzing a third delay (ie delivery of adequate care within the health facility), we assessed the care at the first admission to a facility and at the referral hospital, including timely recognition, appropriate management and treatment delay, and any delays in transfer to another higher-level facility. Lack of effective and timely care at any of these time points may aggravate a patient's condition and result in a poor outcome. ${ }^{26-29}$ In most of the reviewed cases, we found either delays in referral, referral to a facility not capable of providing the required level of care, or both. For example, facilities that managed the miscarriages and related complications, such as bleeding and uterus perforation leading to maternal death, were basic maternity units with limited capacity to handle such complications or to stabilize the patient before referring to another facility.

We found substandard care in which improvements would have made a difference to the outcome in 13 $(87 \%)$ of early and two $(67 \%)$ of the three late maternal deaths from direct obstetric causes. The findings are in line with UK confidential enquiries to maternal deaths and studies from Netherlands which identified that improvements in care would have made a difference to outcomes for over $90 \%$ of women who died..$^{30,31}$

Sepsis or septic shock was the most common underlying direct cause of maternal deaths in Georgia in 2012. Substandard care wherein improvements could have made a difference to the outcome was found across all sepsis cases. Delay in recognition and diagnosis of sepsis was responsible for majority of maternal deaths from sepsis documented by our study. This agrees with findings from other countries. ${ }^{32}$ Achieving a low sepsis-associated mortality is based on rapid triage using a risk-scoring system and early therapy, including appropriate antibiotic treatment within one hour of a suspected diagnosis. ${ }^{33,34}$ As such, obstetricians should maintain a higher level of alert and provide information to pregnant and postpartum women on the importance of seeking timely medical care. Moreover, the best care for sepsis is multidisciplinary; that is, where different specialists are involved in case management at early stage of case identification. ${ }^{17}$ A multidisciplinary approach should become a standard of care for Georgia as well, in addition to wide-scale adherence to basic principles of patient care; namely, 
regular measuring, monitoring and recording of full spectrum of vital parameters, and strict infection control. In line with some other studies, ${ }^{35,36}$ we found more maternal sepsis among younger women and in women delivered by caesarean section. Post-operative infection was the source of sepsis in our study, while respiratory infections were dominant sepsis cases in the maternal health studies from the high-income countries. ${ }^{3}$

Inadequate antibacterial prevention and/or timely treatment was the main element of substandard care we found by our study. Routine antibiotic use prior to the initiation of or during caesarean section is recommended for women undergoing caesarean section. ${ }^{20}$ No antibiotic prophylaxis was provided in either of the three women who delivered via caesarean section and who died from sepsis or septic shock. The medical records review of these women does not provide evidence of clinical signs of sepsis prior to the surgery. Our data point to the fact that sepsis represents a major threat to maternal health in Georgia, and that there is frequently late recognition then suboptimal care. Thus, improvements in this area are urgent.

Whilst the number of women who died from pregnancy induced hypertension was low in our study, substandard care was evident for these women. Important opportunities are present to further improve care, prevent deaths and reduce morbidity from pregnancy induced hypertension. Identifying women with risk factors ${ }^{21}$ is important for early recognition as well as proper antenatal care, referral, and appropriate management. In our study, risk factors were present in both cases of preeclampsia. However, no increased schedule of antenatal care for these women with pre-existing hypertension was provided, and no visits were scheduled between 28 and 33 weeks of gestation. This is too long a time period without medical contact for the high-risk women.

In Georgia, a full assessment for pre-eclampsia or HELLP syndrome, including a spectrum of blood tests, is strongly recommended in women presenting with symptoms or signs of this syndrome. Yet, in our study, neither woman received proper laboratory tests, imaging investigations or treatment, according to the national clinical practice guidelines. Poor compliance with evidence-based clinical practice guidelines and protocols, as demonstrated by our study, remains a challenge in Georgia and across many countries. Multi-faceted, tailored solutions, going beyond simple dissemination of guidelines/protocols should be extensively implemented by Georgia to increase compliance with existing evidence-based protocols. Some
European countries, such as UK and Norway, which began implementing targeted interventions to lower avoidable maternal mortality over the last decade, have reached 10 fold reductions in deaths from pre-eclampsia and eclampsia or have achieved a zero level of maternal deaths from preeclampsia. Maternal death inquiries of previous years in these countries identified substandard care of hypertensive complications. ${ }^{4,37,38}$

Pregnancy and particularly the delivery mode by cesarean section increases the risk of thromboembolism, further aggravated in the immediate postpartum period. Thromboembolism was the third major cause of maternal deaths in our study. We identified substandard care in at least two of the three maternal deaths due to thromboembolism. Suggested preventive interventions include early pregnancy and postpartum risk assessment for thromboembolism and thromboprophylaxis with low-molecular weight heparin after cesarean delivery in women with risk factors (other than previous venous thromboembolism or thrombophilia). ${ }^{18,19}$ Most importantly, timely referral is recommended for all pregnant or postpartum women who complain of newly emerged dyspnea, for evaluation of thromboembolism or pulmonary embolism. ${ }^{18}$

Delay in the diagnoses and adequate management of maternal hemorrhage are important substandard care factors that may lead to severe maternal morbidity or death. ${ }^{39}$ Several studies have found that most deaths from hemorrhage are preventable. ${ }^{7,40,41}$ Early recognition and adequate assessment of blood loss in the management of obstetric hemorrhage is the cornerstone of care. In our study, blood loss was significantly underestimated in all three maternal deaths from hemorrhage. In addition, the clinical management did not comply with the national clinical practice guidelines. In the case of major obstetric hemorrhage, there should be no delay in surgical management. While no other surgical management procedures were used before opting for hysterectomy, all three women in our study underwent delayed hysterectomy. The strategies for blood transfusion also were inadequate. Furthermore, the risk of postpartum hemorrhage can be reduced by $60 \%$ with active management of the third stage of labor and routine administration of prophylactic uterotonic drugs immediately after delivery. ${ }^{22}$ Despite strong recommendations in force, there is still a significant variation in uterotonic drug practices in Georgia.

The bundle approach ${ }^{42-44}$ recently has been proposed as an intervention to address suboptimal adherence to hemorrhage and other clinical practice guidelines and to 
improve the quality of care. Further, staff education and simulation exercises could help to improve accuracy of the blood loss measurement. ${ }^{45,46}$ Unfortunately, no quality of care improvement strategies or continuous medical education and audits with multidisciplinary morbidity and mortality reviews were required or implemented by health facilities in Georgia at the time of the study period.

Our findings from Georgia highlight the need for improvements in quality of obstetric care to reduce maternal deaths. Since 2015, several initiatives have been implemented to reduce avoidable maternal deaths. These initiatives include in-service training courses for obstetrician-gynecologists, midwives and intensive care specialists and the updating of national clinical practice guidelines. Health systems improvements have been implemented. They aim to regionalize specialized maternal and newborn care services and create a coordinated system of care between different facility levels. These efforts led to improvements in facility infrastructures, scope of practice and definition of competencies at each level along with a greatly strengthened referral system. Further acceleration of these initiatives and systemic changes to improve the quality of care offer a strong hope of decreasing in preventable maternal mortality.

One of the strengths of our study lays in the opportunity to interview family members to get the details of each patient's case and thus providing a reliable clinical timeline prior to the maternal death. The study was also strengthened by a comprehensive methodology likely to include all deaths within a year of abortion and nonfacility deaths, with no or less likely missing number of deaths of WRA within a year following delivery. The study also had the advantage of being able to access and use data from hospitalizations during pregnancy and one year before the fatal event. However, the study did not include a detailed review of medical records or characteristics of care for late maternal deaths due to indirect causes. Additionally, postmortem autopsies -important to examine the cause and factors that contribute to death ${ }^{47}$ were not performed in any of the 23 maternal death cases, due mainly to cultural challenges related with postmortem autopsy practices in Georgian society.

\section{Conclusions}

Most maternal deaths which were analyzed in this study were potentially preventable. The clear implication is that improvements in the quality of care are necessary to reduce maternal mortality. While we recognize that evaluation of substandard care may lack robustness, the cases of maternal mortality in our study illustrate the presence of failures in quality of care such as delayed and misdiagnoses, inadequate treatment, failure to follow national protocols and delays or inappropriate referrals to manage obstetric emergencies. Comprehensive, multi-dimensional, proactive strategies are of paramount importance to implement efforts to address these challenges and to minimize preventable maternal deaths. Recommended actions include: (1) routine periodic national analyses and monitoring of maternal deaths; (2) establishing an internal (facility-based) clinical audit system to guide the design of obstetric interventions and policies; (3) enhancing active surveillance for identification and registration of late maternal deaths; (4) improving routine postpartum care focusing on early recognition of complications to reduce late maternal deaths; (5) introducing a mandatory continuous medical education system; (6) implementing quality improvement initiatives to address modifiable risk factors; and (7) introducing mechanisms to reward quality and safety of maternity care, including financial incentives for measured quality of care and public reporting of healthcare quality data.

\section{Ethics}

The study was conducted in accordance with the Helsinki Declaration.

\section{Acknowledgments}

The authors thank the US Agency for International Development (USAID) for funding this study and Letten Foundation for providing financial support for this work. The authors are also grateful to the staff of NCDC\&PH and all other contributors to this study. The funding agency had no role in the study design and data collection, data analysis, or preparation of this manuscript.

\section{Author Contributions}

All authors made substantial contributions to conception and design, acquisition of data, or analysis and interpretation of data; took part in drafting the article or revising it critically for important intellectual content; agreed to submit to the current journal; gave final approval of the version to be published; and agree to be accountable for all aspects of the work. 


\section{Disclosure}

Dr Nino Berdzuli reports grants from United States Agency for International Development and that the US International Development Agency funded the Reproductive Age Mortality Survey study and data from this study were used to analyze maternal deaths, during the conduct of the study. The authors declare that they have no other potential conflicts of interest for this work.

\section{References}

1. World Health Organization. Trends in maternal mortality 2000 to 2017. Estimates by WHO, UNICEF, UNFPA, World Bank Group and the United Nations Population Division. 2019. Available from: https://www.who.int/reproductivehealth/publications/maternalmortality-2000-2017/en/. Accessed July 12, 2020.

2. Say L, Chou D, Gemmill A, et al. Global causes of maternal death: a WHO systematic analysis. Lancet Glob Health. 2014;2(6):e323333. doi:10.1016/S2214-109X(14)70227-X

3. Knight M, Nair M, Tuffnell D, et al. Saving Lives, Improving Mothers' Care - Surveillance of Maternal Deaths in the UK 201214 and Lessons Learned to Inform Maternity Care from the UK and Ireland Confidential Enquiries into Maternal Deaths and Morbidity 2009-14. Oxford: National Perinatal Epidemiology Unit, University of Oxford; 2016. Available from: https://www.npeu.ox.ac.uk/down loads/files/mbrrace-uk/reports/MBRRACE-UK\%20Maternal\% 20Report\%202016\%20-\%20website.pdf. Accessed July 10, 2020.

4. Vangen S, Bødker B, Ellingsen L, et al. Maternal deaths in the Nordic countries. Acta Obstet Gynecol Scand. 2017;96(9):1112-1119. doi:10.1111/aogs.13172

5. Calvello EJ, Skog AP, Tenner AG, Wallis LA. Applying the lessons of maternal mortality reduction to global emergency health. Bull World Health Organ. 2015;93(6):417-423. doi:10.2471/BLT.14.146571

6. Wagstaff A, Claeson M. The Millennium Development Goals for Health: Rising to the Challenges. Washington: World Bank; 2004. Available from: https://openknowledge.worldbank.org/bitstream/han dle/10986/14954/296730PAPER0Mi1 ent0goals0for0health.pdf? sequence $=1 \&$ is Allowed $=y$. Accessed July 13, 2020.

7. Bowyer L. The Confidential Enquiry into Maternal and Child Health (CEMACH). Saving Mothers' Lives: reviewing maternal deaths to make motherhood safer 2003-2005. The Seventh Report of the Confidential Enquiries into Maternal Deaths in the UK. Obstet Med. 2008;1(1):54. doi:10.1258/om.2008.080017

8. Maruthappu M, Ng KYB, Williams C, Atun R, Agrawal P, Zeltner T. The association between government healthcare spending and maternal mortality in the European Union, 1981-2010: a retrospective study. BJOG. 2015;122:1216-1224.

9. Donabedian A. The quality of care: how can it be assessed? JAMA. 1988;260(12):1743-1748.

10. Institute of Medicine (US) Committee on Quality of Health Care in America. Crossing the Quality Chasm: A New Health System for the 21st Century. Washington (DC): National Academies Press (US); 2001. Available from: https://pubmed.ncbi.nlm.nih.gov/25057539/. Accessed August 10, 2020.

11. GBD. 2015 Maternal Mortality Collaborators. Global, regional, and national levels of maternal mortality, 1990-2015: a systematic analysis for the Global Burden of Disease Study 2015. The Lancet. 2016;388(10053):1775-1812. doi:10.1016/S0140-6736(16)31470-2.

12. World health Organization. Maternal Death Surveillance and Response. Technical Guidance. Information for action to prevent maternal death. 2013. Available from: https://www.who.int/mater nal_child_adolescent/documents/maternal_death_surveillance/en/. Accessed July 23, 2020.
13. Donati S, Maraschini A, Lega I, D’Aloja P, Buoncristiano M, Manno V. The Regional Maternal Mortality Working Group. Maternal mortality in Italy: results and perspectives of record-linkage analysis. Acta Obstet Gynecol Scand. 2018;97(11):1317-1324. doi:10.1111/aogs.13415

14. Høj L, Da Silva D, Hedegaard K, Sandström A, Aaby P. Maternal mortality: only 42 days? BJOG. November. 2003;110(11):995-100022. doi:10.1111/j.1471-0528.2003.03007.x

15. Berdzuli N, Lomia N, Staff AC, et al. Maternal mortality in Georgia: incidence, causes and level of underreporting: a national reproductive age mortality study 2014. Int J Women's Health. 2020;12:277-286.

16. World Health Organization. The WHO application of ICD-10 to deaths during pregnancy, childbirth and the puerperium: ICD-MM. 2012. Available from: https://www.who.int/reproductivehealth/publi cations/monitoring/9789241548458/en/. Accessed July 2, 2020.

17. Royal College of Obstetricians and Gynaecologists (RCOG). Bacterial Sepsis in Pregnancy (Green-Top Guideline No. 64a). London: RCOG;2012 April. Available from: https://www.rcog.org.uk/globalas sets/documents/guidelines/gtg_64a.pdf. Accessed August 8, 2020.

18. Royal College of Obstetricians and Gynaecologists (RCOG). Reducing the Risk of Venous Thromboembolism During Pregnancy and the Puerperium (Green-Top Guideline No. 37a). London: RCOG;2015.

19. American College of Obstetricians and Gynecologists (ACOG). Thromboembolism in Pregnancy (ACOG Practice Bulletin No. 196). Obstet Gynecol. 2018;132(1):e1-e17. doi:10.1097/AOG.0000000000 002706.

20. World Health Organization. WHO recommendation on routine antibiotic prophylaxis for women undergoing elective or emergency caesarean section. 2015. Available from: https://extranet.who.int/rhl/ topics/preconception-pregnancy-childbirth-and-postpartum-care/whorecommendation-routine-antibiotic-prophylaxis-women-undergoingelective-or-emergency-caesarean. Accessed August 9, 2020.

21. World Health Organization. WHO recommendations for Prevention and treatment of pre-eclampsia and eclampsia. 2011. Available from: https://www.who.int/reproductivehealth/publications/maternal_perina tal_health/9789241548335/en/. Accessed August 9, 2020.

22. World Health Organization. WHO recommendations: uterotonics for the prevention of postpartum haemorrhage. 2018. Available from: https://apps.who.int/iris/bitstream/handle/10665/277276/ 9789241550420-eng.pdf?ua=1. Accessed August 10, 2020.

23. GBD. 2015 Maternal Mortality Collaborators. Global, regional, and national levels of maternal mortality, 1990-2015: a systematic analysis for the Global Burden of Disease Study 2015. Lancet. 2016;388 (10053):1775-1812. doi:10.1016/S0140-6736(16)31470-2.

24. El-Messidi A, Czuzoj-Shulman N, Spence AR. Medical and obstetric outcomes among pregnant women with tuberculosis: a population-based study of 7.8 million births. Am J Obstet Gynecol. 2016;215(6):797.e1-797.e6. doi:10.1016/j.ajog.2016.08.009

25. European Centre for Disease Prevention and Control/WHO Regional Office for Europe. Tuberculosis surveillance and monitoring in Europe 2017. Surveillance report. 20 March 2017. Available from: https://www.ecdc.europa.eu/sites/default/files/documents/ecdctuberculosis-surveillance-monitoring-Europe-2017-WEB.pdf. Accessed August 11, 2020.

26. Mould-Millman NK, Naidoo R, de Vries S, Stein C, Wallis LA. AFEM Consensus Conference, 2013. AFEM out-of-hospital emergency care workgroup consensus paper: advancing out-of-hospital emergency care in Africa - advocacy and development. Afr J Emerg Med. 2014;4(2):90-95. doi:10.1016/j.afjem.2014.02.001

27. Edson W, Burkhalter B, Harvey S, et al. Safe Motherhood Studies Timeliness of In-Hospital Care for Treating Obstetric Emergencies: Results from Benin, Ecuador, Jamaica, and Rwanda. Washington: United States Agency for International Development;2006. Available from. https://www.researchgate.net/publication/265930411_ SAFE MOTHERHOOD STUDIES- TIMELINESS OF INHOSPITAL_CARE_FOR_TREATING_öBSTETRIC_ EMERGENCIES. 
28. Lambert LJ, Brown KA, Boothroyd LJ, et al. Transfer of patients with ST-elevation myocardial infarction for primary percutaneous coronary intervention: a province-wide evaluation of "door-in to door-out" delays at the first hospital. Circulation. 2014;129 (25):2653-2660. doi:10.1161/CIRCULATIONAHA.113.007130

29. Ifenne D, Essien E, Golji N, et al. Improving the quality of obstetric care at the teaching hospital, Zaria, Nigeria. Int J Gynaecol Obstet. 1997;59 Suppl 2:S37-46.

30. Knight M, Bunch K, Tuffnell D, et al. On Behalf of MBRRACE-UK. Saving Lives, Improving Mothers' Care - Lessons Learned to Inform Maternity Care from the UK and Ireland Confidential Enquiries into Maternal Deaths and Morbidity 2014-16. Oxford: National Perinatal Epidemiology Unit, University of Oxford; 2018. Available from: https://www.npeu.ox.ac.uk/downloads/files/mbrrace-uk/reports/ MBRRACE-UK\%20Maternal\%20Report\%202018\%20-\%20Web\% 20Version.pdf. Accessed July 24, 2020.

31. Schutte JM, Steegers EA, Schuitemaker NW, et al. Rise in maternal mortality in the Netherlands. BJOG. 2010;117:399-406.

32. Cantwell R, Clutton-Brock T, Cooper G, et al. Saving Mothers' Lives: reviewing maternal deaths to make motherhood safer: 2006-2008. The Eighth Report of the Confidential Enquiries into Maternal Deaths in the United Kingdom. BJOG. 2011;118 (Suppl1):1-203. doi:10.1111/j.1471-0528.2010.02847

33. Gaieski DF, Mikkelsen ME, Band RA, et al. Impact of time to antibiotics on survival in patients with severe sepsis or septic shock in whom early goal-directed therapy was initiated in the emergency department. Crit Care Med. 2010;38(4):1045-1053. doi:10.1097/ CCM.0b013e3181cc4824

34. Bauer ME, Housey M, Bauer ST, et al. Risk factors, etiologies, and screening tools for sepsis in pregnant women: a multicenter case-control study. PubMed. 2019;129(6):1613-1620. doi:10.1213/ ANE.0000000000003709

35. Kramer HM, Schutte JM, Zwart JJ, Schuitemaker NW, Steegers EA, van Roosmalen J. Maternal mortality and severe morbidity from sepsis in the Netherlands. Acta Obstet Gynecol Scand. 2009;88:647-653. doi:10.1080/00016340902926734

36. Waterstone M, Bewley S, Wolfe C. Incidence and predictors of severe obstetric morbidity: case-control study. BMJ. 2001;322:1089-1093.

37. Knight M, Tuffnell D, Kenyon S, Shakespeare J, Gray R, Kurinczuk JJ, Eds. On Behalf of MBRRACE-UK. Saving Lives, Improving Mothers' Care - Surveillance of Maternal Deaths in the UK 2011-13 and Lessons Learned to Inform Maternity Care from the UK and Ireland Confidential Enquiries into Maternal Deaths and Morbidity 2009-13. Oxford, UK: National Perinatal Epidemiology Unit, University of Oxford;2015. Available from: https://www.npeu.ox.ac.uk/downloads/files/mbrrace-uk /reports/MBRRACE-UK\%20Maternal\%20Report\%202015.pdf. Accessed August 9, 2020.
38. Nyfløt L, Ellingsen L, Branka M, Yli BM, Øian P, Vangen S. Maternal deaths from hypertensive disorders: lessons learnt. Acta Obstet Gynecol Scand. 2018. doi:10.1111/aogs.13357

39. Lu MC, Fridman M, Korst LM, et al. Variations in the incidence of postpartum hemorrhage across hospitals in California. Matern Child Health J. 2005;(3):297-306. doi:10.1007/s10995-005-0009-3.

40. Berg CJ, Harper MA, Atkinson SM, et al. Preventability of pregnancy-related deaths: results of a state-wide review. Obstet Gynecol. 2005;106(6):1228-1234. doi:10.1097/01.AOG.0000187 894.71913.e8

41. Clark SL, Belfort MA, Dildy GA, HerOIbst MA, Meyers JA, Hankins GD. Maternal death in the 21 st century: causes, prevention, and relationship to cesarean delivery. Am J Obstet Gynecol. 2008;199:36.e1-36.

42. Goffman D, Nathan L, Chazotte C. Obstetric hemorrhage: a global review. Semin Perinatol. 2016;40(2):96-98. doi:10.1053/j.semperi. 2015.11.014

43. Althabe F, Therrien MNS, Pingray V, et al. Postpartum hemorrhage care bundles to improve adherence to guidelines: a WHO technical consultation. Int J Gynecology Obstet. 2020;148(3):290-299.

44. California Maternal Quality Care Collaborative. Obstetric Hemorrhage Safety Bundle. CMQCC; 2014 23. Available from: https://www.cmqcc.org/resource/obstetric-hemorrhage-safety-bundle. Accessed August 12, 2020.

45. Toledo P, McCarthy RJ, Burke CA, Goetz K, Wong CA, Grobman WA. The effect of live and web-based education on the accuracy of blood-loss estimation in simulated obstetric scenarios. Am J Obstet Gynecol. 2010;202(4):400.e1-5. doi:10.1016/j.ajog.20 09.10 .881

46. Hancock A, Weeks AD, Lavender DT. Is accurate and reliable blood loss estimation the 'crucial step' in early detection of postpartum haemorrhage: an integrative review of the literature. BMC Pregnancy Childbirth. 2015;15:230. doi:10.1186/s12884-015-0653-6

47. Kavatkar AN, Sahasrabuthe NS, Jadhav MV, Deshmukh SD. Autopsy study of maternal deaths. Int J Gynec Obstet. 2003;81(1):1-8. doi:10.1016/S0020-7292(02)00402-2
International Journal of Women's Health

\section{Publish your work in this journal}

The International Journal of Women's Health is an international, peerreviewed open-access journal publishing original research, reports, editorials, reviews and commentaries on all aspects of women's healthcare including gynecology, obstetrics, and breast cancer. The manuscript management system is completely online and includes a very quick and fair peer-review system, which is all easy to use. Visit http://www.dovepress.com/testimonials.php to read real quotes from published authors. 